\title{
La naturaleza del procedimiento de selección de contratistas y el carácter común de la Ley del Procedimiento Administrativo General ${ }^{(x)}$
}

\section{The nature of the contractor selection procedure and the common nature of the General Administrative Procedure Law}

\author{
Néstor Shimabukuro Tokashiki ${ }^{(* *)}$ \\ Pontificia Universidad Católica del Perú \\ Oscar Alejos Guzmán ${ }^{(* * *)}$ \\ Universidad Nacional Mayor de San Marcos
}

Resumen: La naturaleza especial del procedimiento de selección de contratistas y la jerarquía de fuentes de la Ley de Contrataciones del Estado han sido usadas como argumento para sustentar la inaplicación de la regla de interoperabilidad en el marco de dichos procedimientos. Estando en desacuerdo con dicha posición, sustentamos en el presentamos artículo que la naturaleza especial del procedimiento de selección no niega la aplicación del principio de informalismo que sustenta la regla de interoperabilidad. Asimismo, sostenemos que el carácter común de la Ley del Procedimiento Administrativo General, en donde se consagra el principio de informalismo, obliga a una reinterpretación de la jerarquía de fuentes de la Ley de Contrataciones del Estado.

Palabras Clave: Procedimiento de Selección - Contrataciones con el Estado - Interoperabilidad - Procedimiento administrativo - Procedimiento común

Abstract: The special nature of the contractor selection procedure and the source hierarchy of the State Procurement Law have been used as an argument to support the non-application of the interoperability rule within

$\left.{ }^{*}\right) \quad$ Nota del editor: Este artículo fue recibido el 10 de abril de 2018 y su publicación fue aprobada el 21 de junio de 2018.

$\left({ }^{* *}\right)$ La responsabilidad por las opiniones vertidas es exclusivamente nuestra y no compromete a la institución a la cual estamos vinculados.

$\left(^{* * *}\right)$ Agradecemos los valiosos comentarios del profesor Ramón Huapaya a borradores previos de este trabajo.

${ }^{* * *}$ ) Abogado de la Pontificia Universidad Católica del Perú. Profesor adjunto del curso de Derecho Administrativo Económico en la PUCP. Asociado en CMS Grau. Correo electrónico: nestor.shimabukuro@cms-grau.com

$\left({ }^{* * *}\right)$ Abogado de la Universidad Nacional Mayor de San Marcos (UNMSM). Asociado en CMS Grau. Correo electrónico: oscar. alejos@cms-grau.com 
La naturaleza del procedimiento de selección de contratistas y el carácter común de la Ley del Procedimiento Administrativo General The nature of the contractor selection procedure and the common nature of the General Administrative Procedure Law

the framework of these procedures. Being in disagreement with this position, we sustain in the article that the special nature of the selection procedure does not negate the application of the informalism principle that underpins the interoperability rule. Likewise, we maintain that the common character of the Law of General Administrative Procedure, where the principle of informalism is enshrined, requires a reinterpretation of the hierarchy of sources of the State Contracting Law.

Keywords: Selection procedure - Contracting with the State Interoperability - Administrative procedure - Common procedure

Sumario: 1. Introducción_2. La naturaleza del procedimiento de selección_3. La interoperabilidad como medida de simplificación administrativa y su compatibilidad con el procedimiento de selección_ 4. El carácter común de la LPAG y la jerarquía de fuentes en la LCE_5. Conclusión_6. Referencias bibliográficas.

\section{Introducción. A propósito de una opinión del Organismo Supervisor de Contrataciones con el Estado (OSCE)}

En el año 2016 se emitieron diversas normas que modificaron el ordenamiento jurídico administrativo peruano, entre ellas, la más relevante es el Decreto Legislativo No 1272 que modificó la Ley 27444 - Ley del Procedimiento Administrativo General (En adelante, LPAG). Nota importante de esta norma es que precisó el carácter común de la LPAG(1), es decir, su prevalencia respecto de las leyes que regulen procedimientos especiales.

Sin embargo, no menos importante fue la emisión del Decreto Legislativo No 1246, norma que estableció distintos mecanismos de simplificación administrativa, entre los que destaca la interoperabilidad (2). La idea esencial detrás del concepto es que la Administración es una sola, de manera que los documentos que se presenten a una entidad o que ésta haya generado, se deben entender en poder de todas las demás. Inspiran esta noción los principios de celeridad, simplicidad, eficacia e informalismo ${ }^{(3)}$, consagrados positivamente en el Artículo IV de la LPAG.

Por su parte, destaca también el Decreto Legislativo No 1311 que modificó la Ley de

(1) Artículo II.- Contenido

1. La presente Ley contiene normas comunes para las actuaciones de la función administrativa del Estado y, regula todos los procedimientos administrativos desarrollados en las entidades, incluyendo los procedimientos especiales.

2. Las leyes que crean y regulan los procedimientos especiales no podrán imponer condiciones menos favorables a los administrados que las previstas en la presente Ley.

3. Las autoridades administrativas, al reglamentar los procedimientos especiales, cumplirán con seguir los principios administrativos, así como los derechos y deberes de los sujetos del procedimiento, establecidos en la presente Ley.

(2) Artículo 2.- Interoperabilidad entre entidades de la Administración Pública

Dispóngase que las entidades de la Administración Pública de manera gratuita, a través de la interoperabilidad, interconecten, pongan a disposición, permitan el acceso o suministren la información o bases de datos actualizadas que administren, recaben, sistematicen, creen o posean respecto de los usuarios o administrados, que las demás entidades requieran necesariamente y de acuerdo a ley, para la tramitación de sus procedimientos administrativos y para sus actos de administración interna. En los casos en los que la información o datos se encuentren protegidos bajo la Ley № 29733, Ley de Protección de Datos Personales, las entidades de la Administración Pública deben obtener la autorización expresa e indubitable del usuario o administrado para acceder a dicha información o datos.

(3) Artículo IV. Principios del procedimiento administrativo

1. El procedimiento administrativo se sustenta fundamentalmente en los siguientes principios, sin perjuicio de la vigencia de otros principios generales del Derecho Administrativo:

1.6. Principio de informalismo.- Las normas de procedimiento deben ser interpretadas en forma favorable a la admisión y decisión final de las pretensiones de los administrados, de modo que sus derechos e intereses no sean afectados por la exigencia de aspectos formales que puedan ser subsanados dentro del procedimiento, siempre que dicha excusa no afecte derechos de terceros o el interés público.

1.9. Principio de celeridad.- Quienes participan en el procedimiento deben ajustar su actuación de tal modo que se dote al trámite de la máxima dinámica posible, evitando actuaciones procesales que dificulten su desenvolvimiento o constituyan 


\section{Néstor Shimabukuro Tokashiki y Oscar Alejos Guzmán}

Contrataciones del Estado recientemente aprobada mediante Ley 30225 (LCE). Entre las diversas modificaciones realizadas por el mencionado decreto, queremos poner énfasis en la precisión realizada en la Primera Disposición Complementaria Final que en su versión original establecía que "la presente ley y su reglamento prevalecen sobre las normas de derecho público y sobre todas de derecho privado que le sean aplicables". Ahora, el texto ha quedado redactado como sigue: "La presente ley y su reglamento prevalecen sobre las normas del procedimiento administrativo general, de derecho público y sobre todas de derecho privado que le sean aplicables".

Pues bien, desde la aprobación de la LCE y antes incluso durante la vigencia de la norma anterior, las Bases Estándar aprobadas mediante Directivas del OSCE, establecen que la acreditación de facultades se realiza con la presentación de una vigencia de poder emitida por Registros Públicos. Evidentemente, si aplicáramos la regla de interoperabilidad, dicha exigencia debería considerarse eliminada, estando prohibidas las entidades públicas de requerir dicho documento.

En ese sentido, las normas que hemos descrito entran en conflicto. Así lo considera la Dirección Técnico Normativa del Organismo Supervisor de las Contrataciones del Estado (OSCE), órgano competente para absolver las consultas de los administrados respecto de las normas que rigen la contratación pública. Sin embargo, contrariamente de lo que hemos indicado en el párrafo anterior, a criterio de dicha Dirección - materializado en la Opinión No 081-2017/DTN y otras - la regla de interoperabilidad resulta inaplicable para los procesos de selección de contratistas.

La línea de argumentativa de la Dirección se basa en la Primera Disposición Complementaria Final de la LCE, lo que le permite concluir lo siguiente:

\begin{abstract}
"En ese sentido, la normativa de contrataciones del Estado prevalece sobre las normas del procedimiento administrativo general, como por ejemplo el Decreto Legislativo $\mathrm{N}^{\circ} 1246$, por lo que siguen vigentes las disposiciones contenidas en Reglamento y las Bases Estándar en lo referido a la forma de acreditar los requisitos de calificación referidos a la capacidad legal".
\end{abstract}

En las líneas siguientes, pretendemos demostrar que dicha opinión es equivocada y parte de una concepción errada de la naturaleza del procedimiento de selección. Asimismo, pretendemos demostrar que no existe incompatibilidad entre lo dispuesto en el Artículo II del Título Preliminar de la LPAG y la Primera Disposición Complementaria Final de la LCE.

\section{La naturaleza del procedimiento de selección}

Si bien no lo desarrolla de forma expresa, la opinión de la Dirección Técnico Normativa del OSCE parte de una premisa respecto de la naturaleza del procedimiento de selección de contratistas. En efecto, implícitamente la Dirección sostiene que dicho procedimiento es distinto del procedimiento administrativo para el que fue pensada la interoperabilidad:

"El Decreto Legislativo No 1246 constituye una norma que se aplica a

meros formalismos, a fin de alcanzar una decisión en tiempo razonable, sin que ello releve a las autoridades del respeto al debido procedimiento o vulnere el ordenamiento.

1.10. Principio de eficacia.- Los sujetos del procedimiento administrativo deben hacer prevalecer el cumplimiento de la finalidad del acto procedimental, sobre aquellos formalismos cuya realización no incida en su validez, no determinen aspectos importantes en la decisión final, no disminuyan las garantías del procedimiento, ni causen indefensión a los administrados. En todos los supuestos de aplicación de este principio, la finalidad del acto que se privilegie sobre las formalidades no esenciales deberá ajustarse al marco normativo aplicable y su validez será una garantía de la finalidad pública que se busca satisfacer con la aplicación de este principio.

1.13. Principio de simplicidad.- Los trámites establecidos por la autoridad administrativa deberán ser sencillos, debiendo eliminarse toda complejidad innecesaria; es decir, los requisitos exigidos deberán ser racionales y proporcionales a los fines que se persigue cumplir. 


\section{La naturaleza del procedimiento de selección de contratistas y el carácter común de la Ley del Procedimiento Administrativo General The nature of the contractor selection procedure and the common nature of the General Administrative Procedure Law}

los procedimientos administrativos que lleven a cabo las Entidades, mientras que la normativa de contrataciones del Estado constituye una normativa especial que se emplea en los procesos de contrataciones de bienes, servicios y obras que realizan las Entidades".

Siendo esta la premisa de la cual parte la Dirección, consideramos imprescindible aclarar cuál es la verdadera naturaleza del procedimiento de selección de contratistas y en qué se diferencia del procedimiento administrativo.

Desde el punto de vista estructural, el procedimiento administrativo es un complejo de actos vinculados por su carácter instrumental respecto de un fin común de interés público ${ }^{(4)}$.

Adicionalmente a la perspectiva estructural, como bien apunta la doctrina desde hace ya varios años (García de Enterría y Fernández 2002, 442), el procedimiento administrativo es ante todo una garantía para el administrado, dado que "supone que la actividad de la Administración tiene que canalizarse obligadamente a través de unos cauces determinados como requisito mínimo para que pueda ser calificada de actividad legítima".

En sentido similar ha indicado Tawil que la regulación del procedimiento administrativo no sólo es un instrumento de control del proceso de formación de la voluntad de la Administración, sino a su vez constituye un mecanismo que permite "otorgar a los administrados la posibilidad de hacer valer sus derechos o intereses frente al abuso o funcionamiento deficiente de la organización estatal" (Tawil 2010, 3) ${ }^{(5)}$.

Sobre la base de dichas precisiones es que debe tomarse en cuenta que la regulación de todo procedimiento administrativo debe considerarse desde la perspectiva de ser una garantía para el administrado y no una estructura compleja de requisitos, plazos y exigencias que buscan hacer más difícil la obtención de un pronunciamiento por parte de la autoridad pública.

Ahora bien, tomando ello en cuenta, no existen mayores problemas para catalogar el procedimiento de selección de contratistas como un procedimiento administrativo. En efecto, estructuralmente estamos frente a un complejo de actos del administrado (por ejemplo, la observación de las bases y la presentación de la oferta) y Administración (por ejemplo, la convocatoria, la emisión de las bases y la evaluación de las ofertas), vinculados por una finalidad común de interés público: la adjudicación de un contrato público que busca satisfacer una necesidad de bienes, servicios u obras de la Administración ${ }^{(6)}$.

Asimismo, la regulación del procedimiento de selección de contratistas constituye no sólo un cauce formal para garantizar la legitimidad de la adquisición o contratación estatal, sino que además busca garantizar los derechos de los postores-administrados, derivados de los principios de concurrencia e igualdad ${ }^{(7)}$.

En ese sentido, no existe razón para sostener que el procedimiento de selección de contratistas no sería propiamente un

(4) Cónfer. García de Enterría y Fernández, 2002: 448. En sentido similar, Cassagne, 2017: 18.

(5) En sentido similar, nos decía Escola, que junto a la finalidad de "asegurar la mayor eficiencia, acierto y corrección, incluso técnica, del accionar administrativo. (...) La otra finalidad del procedimiento administrativo es constituirse en una verdadera garantía jurídica, instituida en favor de los particulares, en defensa de sus derechos subjetivos y sus intereses legítimos, en cuanto pudieran resultar afectados por la actividad de la administración pública", 1973: 22. En la actualidad, puede verse lo escrito por Eduardo Gamero y Severiano Fernández que nos hablan del procedimiento como garantía de los derechos de los administrados y garantía del interés público, 2016: 423-424.

(6) Cónfer. Juan Carlos Cassagne: “La selección del contratante privado encuentra en la 'licitación pública' el cauce general de la contratación administrativa, que se configura, básicamente, como un procedimiento por el cual, mediante una convocatoria o llamado a los eventuales interesados para que formulen sus propuestas con arreglo a un pliego de condiciones, la Administración elige o acepta la que resulte más conveniente", 2009: 68-69.

(7) Cónfer. Eduardo García de Enterría y Tomás-Ramón Fernández: "La selección de los contratistas privados por la Administración ha remitido siempre, como regla general, a fórmulas de licitación pública con las cuales pretendía garantizarse 


\section{Néstor Shimabukuro Tokashiki y Oscar Alejos Guzmán}

procedimiento administrativo. Incluso si aceptáramos que la Dirección Técnico Normativa del OSCE sólo quiso expresar una contraposición entre el procedimiento administrativo regulado en la LPAG y el procedimiento de selección de contratistas, igualmente debemos negar dicha afirmación. En efecto, en realidad no existe dicha contraposición, sino simplemente una relación entre procedimiento especialprocedimiento general.

Siendo ello así, podemos calificar al procedimiento de selección como un procedimiento administrativo de oficio y formalizado tendiente a satisfacer una necesidad del Estado en bienes, servicios u obras, pero un procedimiento al fin y al cabo. Por ello, Morón, en su propuesta de clasificación de procedimientos administrativos, incluye a los procedimientos de selección de contratistas en los procedimientos de oficio, específicamente aquellos mediante los cuales se busca satisfacer una necesidad propia de la Administración, como las subastas o la ejecución coactiva (Morón 2011, 223).

Del mismo modo, el autor precitado incluye los procedimientos de selección entre los procedimientos formalizados, entendiendo por tales a aquellos que "tienen una secuencia procedimental regimentada por la ley, de modo que poseen un orden lógico formal prescrito en la norma que se impone rigurosamente al instructor del procedimiento y apareciendo de algún modo la regla de la preclusión procesal entre las fases del procedimiento" (Morón 2011, 228).

Tomando en cuenta ello, somos de la opinión que no existe diferencia sustancial entre el procedimiento administrativo general y el procedimiento de selección de contratistas. Es cierto que éste es un procedimiento especial que se rige esencialmente por la LCE en lo que respecta a plazos, estructura del procedimiento, entre otros. Sin embargo, se trata de procedimientos que comparten la misma naturaleza de cauce para la manifestación de la voluntad de la Administración Pública materializada en un acto administrativo y, a su vez, comparten la naturaleza de garantía para el administrado.
Precisamente sobre la base de ello es que los principios informadores del procedimiento no pueden ser distintos en uno y otro procedimiento. Si bien su aplicación en cada caso puede ser distinta por la naturaleza disímil de las situaciones, ello no implica que sean inaplicables.

Es más, reiteramos que para la aplicación distinta de un principio debe haber una razón que así lo justifique. Dicho ello, no existe razón alguna para considerar que por la especial naturaleza del procedimiento de selección de contratistas (que no deja de ser un procedimiento administrativo) se debe dejar de aplicar la regla de interoperabilidad que materializa el principio de informalismo recogido en la LPAG.

\section{La interoperabilidad como medida de simplificación administrativa y su compatibilidad con el procedimiento de selección}

Lo expuesto hasta aquí nos permite sostener que el procedimiento de selección de contratistas es, al final del día, un procedimiento administrativo. En ese sentido, la premisa de la cual parte la opinión de la Dirección Técnico Normativa del OSCE carece de sustento.

Ahora bien, es cierto que estamos frente a un procedimiento especial; sin embargo, queda pendiente saber si dicha naturaleza especial legitima la inaplicación de la regla de interoperabilidad.

tanto la igualdad de los particulares como la obtención por la Administración, a través de la competencia, de las condiciones más ventajosas para el interés público", 2002: 711. En sentido similar, Juan Carlos Cassagne: "Por lo general, los contratos que celebra la Administración con personas privadas o públicas no estatales se instrumentan a través de un procedimiento formal que presenta una serie de variantes según el grado de concurrencia y de igualdad que admita cada uno", $2009: 62$. 


\section{La naturaleza del procedimiento de selección de contratistas y el carácter común de la Ley del Procedimiento Administrativo General The nature of the contractor selection procedure and the common nature of the General Administrative Procedure Law}

En nuestra opinión, la naturaleza especial del procedimiento de selección de contratistas justifica la existencia de distintas reglas específicas como la preclusión de los plazos y las formalidades de las exigencias para calificar la experiencia de los postores. Ello, en la medida que dichas reglas especiales se basan en los principios de igualdad y concurrencia que informan las contrataciones del Estado (Marienhoff 1966, 201-203).

Sin embargo, para el caso concreto de la acreditación de facultades (supuesto en el cual se aplicaría la interoperabilidad), no existen ni razones de igualdad ni de promoción de la concurrencia que permitan sostener que la especialidad del procedimiento necesita de la inaplicación de la interoperabilidad.

En efecto, conforme al Decreto Legislativo No 1246, la interoperabilidad implica la creación de determinados derechos a favor de los administrados, esencialmente, a la no presentación de documentos; y, por su parte, implica también la creación de deberes en cabeza de las entidades de la Administración Pública, básicamente a poner a disposición de otras entidades la información o base de datos actualizadas que administren, recaben, sistematicen, creen o posean respecto de los administrados; y, la consecuente prohibición de exigir dicha información a los administrados en los procedimientos que tramiten.

Esta regla se sustenta en los principios de simplificación administrativa que informan el procedimiento administrativo, como los principios de simplicidad, informalismo, eficacia, entre otros. Entonces, la pregunta es si dichos principios no son acaso aplicables al procedimiento de selección.

Como hemos visto en el apartado anterior, el procedimiento de selección es un procedimiento formalizado. Ello no quiere decir que las reglas de informalismo sean inaplicables. Por el contrario, lo único que se pretende decir señalando que estamos frente a un procedimiento formalizado es que las etapas del mismo se encuentran perfectamente detalladas.
En ese sentido, Gonzáles Navarro, nos explica que "hay casos en que el fin que persigue la actuación administrativa ha de lograrse siguiendo un cauce ritual diseñado por el legislador, el cual ha indicado en qué orden y en qué momento han de realizarse todos y cada uno de los trámites que integran el procedimiento de que se trate (procedimientos formalizados)" (Gonzáles 1981:416).

Sobre la base de ello, consideramos que no existe razón para negar la aplicación del principio de informalismo ${ }^{(8)}$ a un procedimiento formalizado como el procedimiento de selección de contratistas. Vale notar que así también lo ha reconocido la Sala de Derecho Constitucional y Social Permanente de la Corte Suprema en la Sentencia de Casación No 8502-2015-LIMA del 29 de noviembre de 2016, en donde se precisó lo siguiente:

“(...) las entidades del Estado a través de los procedimientos especiales y sus reglamentos, no pueden dejar de observar y cumplir los principios administrativos regulados en la Ley No 27444, ni imponer condiciones menos favorables a los administrados que las contenidas en dicha Ley.

\section{$(\ldots)$}

Siendo así, corresponde analizar si la subsanación de tal error formal y subsanable, causaría la afectación de los derechos de terceros o del interés público, a efecto de no colisionar con el principio de informalismo antes citado, resultando que nos encontramos ante una subasta inversa, donde el ganador de la buena pro sería quien presente la propuesta de

(8) En palabras que compartimos, nos dice Gordillo: "Por lo demás, resulta evidente que si la licitación es, como uniformemente se admite, un procedimiento administrativo, resulta necesario explicar por qué habría de constituir una excepción a las reglas generales de dicho procedimiento, una de las cuales precisamente el del informalismo", 1992: 56. 


\section{Néstor Shimabukuro Tokashiki y Oscar Alejos Guzmán}

precio más baja en relación a los precios propuestos por la administración, es decir, que la propuesta económica del demandante, y que no ha sido variada, fue menor a la de las otras empresas postulantes, por tanto, no se advierte afectación a los derechos de éstas, ni al interés público, en tanto ganó la propuesta que otorgaba mayores beneficios al Estado, máxime si el proceso fue público y todos los postores tuvieron acceso a los documentos del proceso de selección, por lo que el Comité Especial debió otorgar a la demandante el plazo de 1 o 2 días para la subsanación del error formal en que incurrió".(9)

Como puede apreciarse, frente a un caso en donde se discutía la naturaleza de un error en las propuestas, la Corte Supremo no dudó en aplicar el principio de informalismo para resolver, partiendo de la premisa que se trata de un principio plenamente aplicable a los procedimientos de selección.

Es cierto que, a fin de no perjudicar la igualdad y concurrencia de postores, no se pueden relajar en extremo las formas del procedimiento. Sin embargo, teniendo ello en consideración, debe diferenciarse en qué etapa del procedimiento se debe ser más formal(10) que en otras.

En efecto, aun cuando se considere que, en este tipo de procedimiento, debe privilegiarse ciertas formalidades por el objeto del mismo, es decir, la selección de un contratista que satisfaga las necesidades de bienes, servicios y obras del Estado; debe igualmente reconocerse que esas formalidades no son aplicables en todos los extremos del procedimiento. En ese sentido, es necesario recordar que un procedimiento concurrencial como éste no se protege la competencia por representar un valor en sí mismo, sino porque a través de ella se consigue el mejor resultado, en este caso, el mejor adjudicatario para el Estado. De ahí que resulte imprescindible diferenciar qué formalidades coadyuvan a ello y cuáles no.
Así, no cabe negar que en la evaluación de la experiencia del postor se deben seguir mayores formalidades que en otro procedimiento administrativo, a fin de asegurar que se adjudique la buena pro al mejor postor sin afectar el principio de igualdad. Sin embargo, no puede establecerse la misma rigidez en la evaluación de las facultades de representación del postor. En este caso, no existe mayor diferencia entre el procedimiento de selección y otro tipo de procedimiento administrativo.

Conforme explica Morón, existen dos etapas previas a la adjudicación de la buena pro, es decir, dos etapas diferenciables en el procedimiento de selección de contratistas antes de la emisión del acto administrativo con el que concluye el procedimiento. Estas dos etapas son la admisión de la oferta que implica la verificación de aspectos formales de la propuesta ${ }^{(11)}$ (por ejemplo, la inscripción en el RNP, las facultades de representación o la foliación de la propuesta) y la valoración de la oferta que implica una evaluación de las propuestas, una calificación de las mismas $y$, en base a ello, un orden de prelación de postores (Morón 2016, 546-547).

En el Reglamento de la LCE, podemos diferenciar dichas etapas entre aquella en la que se verifica la "capacidad legal" del postor (Artículo 28) y aquella en la que se verifica la "capacidad técnica", la "experiencia del postor" (Artículo 28) y los "factores de evaluación" que determinan al mejor postor (Artículo 30).

(9) Casación No 8502-2015-LIMA (Juez Ponente Walde Jáuregui) en el Caso Alimentos Procesados Sociedad Anónima C. OSCE.

(10) Hace ya bastantes años, Escola escribía que "el excesivo formalismo lleva, también, a transformar al expediente administrativo, al trámite burocrático, como un dijimos, en un objeto en sí mismo, y no en un medio apto para arribar a la decisión oportuna y legítima que corresponde esperar de la administración", 1973: 134.

(11) Lo mismo cabría decir de las formalidades para la presentación de la propuesta. Al respecto, cabe destacar un estudio de González Navarro, en donde analiza la aplicación de la regla de presentación indirecta de escritos (prevista en la norma general) al procedimiento de selección, 1965:153 y siguientes. 
La naturaleza del procedimiento de selección de contratistas y el carácter común de la Ley del Procedimiento Administrativo General The nature of the contractor selection procedure and the common nature of the General Administrative Procedure Law

La esencia del procedimiento de selección de contratistas como procedimiento especial se encuentra en dicha segunda etapa, dado que es en ese momento en el que la entidad valora las propuestas de los postores para escoger al mejor postor, es decir, a quien se adjudicará la buena pro por satisfacer mejor las necesidades del Estado.

Lo mismo no puede decirse de la primera etapa en donde las exigencias sólo buscan admitir la propuesta, es decir, en donde sólo se verifica que se cumplen los requisitos mínimos para entrar al verdadero procedimiento de selección del mejor postor ${ }^{(12)}$. Siendo ello así, no cabe argumentaren este extremo del procedimiento la "especialidad" del mismo para negar la aplicación del marco general que regula el procedimiento administrativo ${ }^{(13)}$.

\section{El carácter común de la LPAG y la jerarquía de fuentes en la LCE}

Si bien no ha sido objeto de análisis por parte de la Dirección Técnico Normativa del OSCE en la opinión bajo análisis, lo cierto es que la misma ha ignorado una norma fundamental de la LPAG. Como precisamos al inicio, el nuevo texto del artículo II del TUO de la LPAG establece el carácter común de dicha ley respecto de los procedimientos especiales. De forma más expresa, el numeral 2 del referido artículo establece la siguiente prohibición:
"2. Las leyes que crean y regulan los procedimientos especiales no podrán imponer condiciones menos favorables a los administrados que las previstas en la presente Ley".

En ese sentido, no sólo es que la naturaleza especial del procedimiento de selección de contratistas no afecte en nada la aplicación de la regla de interoperabilidad, sino que además no podría hacerlo, en la medida que implicaría imponer una condición menos favorable que las previstas en el marco general.

Vale destacar que la consideración de la LPAG como un piso mínimo de garantías había sido reconocida por la doctrina incluso antes de la aprobación de la disposición mencionada ${ }^{(14)}$. Veamos, por ejemplo, lo que sostenía Morón:

"La principal consecuencia del carácter de norma común de las regulaciones del procedimiento administrativo contenidas en esta Ley es que sus disposiciones poseen la vocación de no ser desplazables por ninguna norma administrativa o interpretación

(12) En el mismo sentido se pronunciaba Gordillo: "De cualquier modo, cabe destacar que las exigencias cabe sí aplicarlas a su objeto o finalidad, o sea debe considerarse que ellas están fundamentalmente dirigidas a la oferta en sí misma, es decir la prestación propuesta y el precio (calidad, cantidad, según el objeto de la licitación) y no, o no en la misma medida, a las demás condiciones formales (garantías, poderes, constancias de terceros, avales, recibo de la adquisición del pliego, declaraciones juradas, etc.) que debe cumplimentar el oferente con la presentación, que son obviamente de naturaleza secundaria al objeto principal del llamado a la concurrencia de ofertas", 1992:58.

(13) En ese sentido, compartimos plenamente la posición de Morón: "En tal sentido, si bien la particularidad de la materia habilita a la generación de un procedimiento especial, no estará permitida la diferenciación total del ciclo procedimental (desde el inicio hasta la obtención de la resolución firme, incluyendo recursos, reclamaciones, instancias, deberes de las autoridades, etc.), puesto que solo justifica su diferenciación en aquellas secuencias, regulaciones o partes del procedimiento cuya alteración se vincule con la materia especial y no otras. Es decir, no basta que exista una ley especial que otorgue cobertura a un procedimiento especial para que la autoridad administrativa considere que pueda configurarlo libremente de cualquier manera, puesto que la preferencia de la norma general y común operará válidamente en aquellos aspectos que no constituyan la especialidad de la actuación administrativa concernida", 2011: 241.

(14) Sin perjuicio de ello, no puede negarse que existe una tentación inevitable de los distintos órganos de la Administración Pública para apartarse de la norma común. Al respecto, son ilustrativas las palabras de González Navarro (1965:150), si bien escritas en un contexto diferente: "La LPA lleva en sí, desde su gestación, un cáncer que amenaza con acabar con todo lo que ella se propuso. Este cáncer no es otro que el de la oscuridad en la determinación de su propio ámbito de aplicación, oscuridad buscada de intento posiblemente, con objeto de corregir los movimientos de fuga de los distintos órganos y servicios administrativos, celosos de conservar la especialidad de sus procedimientos de actuación, incluso en aquellos casos en que dicha especialidad carece de justificación” 1965:150. 


\section{Néstor Shimabukuro Tokashiki y Oscar Alejos Guzmán}

particular, las que solo pueden complementarla o reglamentarla pero no sustituirla. En verdad estamos ante una verdadera reserva legal para el caso de determinar a los sujetos que quedan vinculados a acatar sus disposiciones.

\section{(...)}

Como se puede apreciar, la calidad de común de las normas del procedimiento reglado en la Ley 27444 responde al objetivo de reservar en exclusiva al Poder Legislativo la determinación de los principios o normas que, por un lado, definen la estructura general del procedimiento que ha de seguirse para el desenvolvimiento y ejecución de la voluntad de la autoridad administrativa, y, por otro, prescriben las garantías mínimas de los particulares en el seno del procedimiento de la Administración Pública para estructurar el debido procedimiento administrativo" (Morón 2011, 235).

En sentido similar, López Menudo sostiene que "(...) la expresión «procedimiento administrativo común», interpretada en el contexto del artículo 149 de la Constitución, cobra una acepción unívoca en el sentido de derecho directamente aplicable, inderogable por hipotéticas leyes territoriales o especiales, excluyendo a radice, por tanto, la idea de supletoriedad (López 1992, 67)". Y más adelante indica que "El cometido de la ley procedimental común es abordar toda cuestión verdaderamente nuclear, al servicio directo del fin que ha de guiar, a nuestro juicio, toda la hermenéutica sobre este tema: el establecimiento de un común denominador normativo, suficiente para garantizar una básica igualdad de trato" (López 1992, 74).

En ese sentido, la naturaleza especial(15) del procedimiento de selección de contratistas es irrelevante frente al carácter común de la LPAG y sus garantías mínimas. Entre ellas, los principios de informalismo y simplicidad obligan a adoptar la regla de interoperabilidad, de manera que ésta es directamente aplicable a los procedimientos de selección, especialmente a la fase de admisión de propuestas.

Ahora bien, en la opinión bajo análisis se hace referencia a la Primera Disposición Complementaria Final de la LCE que establece que "La presente ley y su reglamento prevalecen sobre las normas del procedimiento administrativo general, de derecho público y sobre todas de derecho privado que le sean aplicables". Sobre la base de ello, la Dirección ha considerado que la regla de interoperabilidad cede frente a la norma especial que ordena acreditar las facultades del representante con una vigencia de poder.

En nuestra opinión, dos argumentos pueden esbozarse en contra: (i) la antinomia existente entre la LPAG y la LCE debe resolverse en función de un criterio de jerarquía axiológica; y, (ii) es posible realizar una interpretación restrictiva de la LCE, considerando que el texto trascrito sólo es aplicable en los extremos en donde el procedimiento de selección de contratistas es genuinamente especial.

En relación al primer argumento, es claro que existe una antinomia entre la LPAG que dispone que sus reglas y principios son preferentes respecto de las reglas previstas para procedimientos especiales y la LCE que dispone que sus reglas especiales son preferentes respecto de las reglas y principios de la LPAG. Vale destacar que en el caso que comentamos, la antinomia se da entre las normas inferiores (aquella de la

(15) Ya antes Víctor Baca había sostenido lo siguiente: “(...) en tanto se necesita del consentimiento del particular, también aquí es posible identificar una potestad administrativa en juego (la distribución de bienes públicos), lo que justificará la existencia de un procedimiento para la formación de la voluntad de la Administración, que se manifiesta a través de actos administrativos, a los que sería aplicable supletoriamente lo dispuesto por la Ley 27444, del Procedimiento Administrativo General" 2014: 275. La aplicación de la LPAG a los procedimientos de selección de contratistas nunca ha estado en discusión. El tema es que ahora las garantías que dicha norma reconoce deben aplicarse de forma directa y obligatoria, no pudiendo calificarse de norma supletoria. 


\section{La naturaleza del procedimiento de selección de contratistas y el carácter común de la Ley del Procedimiento Administrativo General The nature of the contractor selection procedure and the common nature of the General Administrative Procedure Law}

interoperabilidad y aquella de la exigencia de poder) y entre las normas (los teóricos del derecho hablan de meta normas ${ }^{(16)}$ ) que buscan solucionar esa antinomia (aquella de la norma común prevista en la LPAG y aquella de la prelación prevista en la LCE). A esta última antinomia es a la que nos referimos.

Frente a esta antinomia, no cabe aplicar los criterios tradicionales de jerarquía formal (ambas son normas con rango de ley) y especialidad (estamos frente a un binomio norma común-norma particular y no norma general-norma especial).

Si bien podría recurrirse al criterio de temporalidad y privilegiar así la LCE, consideramos que ello no sería adecuado. La razón es que la disposición de la LCE ya existía antes de la modificación del Decreto Legislativo No 1311 (si bien con un texto ligeramente diferente), de manera que uno podría decir que la LPAG (modificada por el Decreto Legislativo No 1272) derogó dicha disposición, solo para que posteriormente el D. Leg. 1311 la volviera a incorporar. Entonces, queda claro que el criterio de temporalidad resulta en este caso palmariamente contingente $\mathrm{y}$, por ende, se sustenta en un argumento poco fuerte.

En cambio, consideramos aplicable un criterio de jerarquía material o valorativa(17), en el entendido que la norma de la LPAG es valorativamente mejor que la norma de la LCE, dado que sólo privilegia la norma común en aquellos aspectos que otorgan más garantías a favor del administrado ${ }^{(18)}$.

Por su parte, en relación al segundo argumento, consideramos que es posible interpretar que el orden de prelación que establece la LCE tiene sentido en la medida que se aplique al extremo que genuinamente es especial en el procedimiento de selección de contratistas. Y, como hemos visto, ello se da sólo en la etapa de evaluación y calificación de ofertas, en donde las actuaciones de administrados-postores y entidades convocantes están sometidas a reglas específicas y especiales que buscan privilegiar los principios de concurrencia e igualdad, propios de la contratación estatal.

Sobre la base de dichas consideraciones, es posible sostener que la jerarquía de fuentes de la LCE no excluye el carácter común de la LPAG que sigue siendo aplicable en lo concerniente a las garantías mínimas del administrado, entre ellas, su derecho a un procedimiento en donde se materialice el principio de informalismo mediante la regla de interoperabilidad.

\section{Conclusiones}

La regla de interoperabilidad constituye un mecanismo de simplificación administrativa que materializa los fines esenciales del principio de informalismo que rige el procedimiento administrativo. En ese sentido, siendo el procedimiento de selección un procedimiento administrativo, su aplicación debe proceder de forma indubitable.

La naturaleza especial del procedimiento de selección no es óbice para la aplicación de la referida regla. En realidad, la especialidad del

(16) "Prima facie, una metanorma es una norma que versa, a nivel de metalenguaje, sobre otra norma" Cónfer. Guastini, 2016: 214.

(17) Las jerarquías materiales "son aquellas que subsisten entre dos normas toda vez que una tercera norma establece que una de las dos primeras es inválida si es incompatible con la otra. (...) La jerarquía en cuestión tiene carácter "material" - es decir, relativa a su contenido - porque influye sobre el contenido de la norma inferior. Es más, aquella consiste precisamente en esto: la norma inferior no puede asumir un contenido que choque (incompatible o antinómico) con aquel de la norma superior" Guastini, 2016: 210. Por su parte, las jerarquías axiológicas "son aquellas que subsisten entre dos normas toda vez que el intérprete atribuye a una de ellas un valor superior al valor de la otra. (...) En definitiva, la relación jerárquica axiológica no depende en modo alguno del contenido de las normas implicadas ni de otras normas del ordenamiento, sino que subsiste solo en virtud de un juicio de valor realizado por el intérprete" Guastini 2016:211-212.

(18) Dejamos constancia que el argumento necesita ser mucho más desarrollado, sobre todo dadas las continuas trasgresiones al carácter común de la LPAG por parte del mismo legislador. Sin embargo, ello amerita la realización de otro trabajo, por lo que la asumimos esa deuda como pendiente. 


\section{Néstor Shimabukuro Tokashiki y Oscar Alejos Guzmán}

referido procedimiento sólo tiene relevancia en la etapa de evaluación de las propuestas y no así en la etapa de admisión que es donde la regla de interoperabilidad despliega sus efectos. Esta distinción es necesaria y permite reafirmar que siendo el procedimiento de selección un procedimiento formalizado, le es aplicable también el principio de informalismo.

Un argumento adicional permite sostener lo dicho y es la naturaleza común de la Ley del Procedimiento Administrativo General que impone sus reglas y principios sobre los procedimientos especiales cuando tutelen de mejor manera las garantías del administrado.

\section{Referencias bibliográficas}

Baca, Víctor. 2014. El concepto, clasificación y regulación de los contratos públicos en el derecho peruano. IUS ET VERITAS No 48.

Cassagne, Juan Carlos. 2009. El Contrato Administrativo. 3 a ed. Buenos Aires: Abeledo Perrot.

Cassagne, Juan Carlos. 2017. Derecho Administrativo. Tomo II. 2a ed. Lima: Palestra.

Escola, Héctor Jorge. 1973. Tratado General de Procedimiento Administrativo. Buenos Aires: Depalma.

Gamero Casado, Eduardo y Fernández Ramos, Severiano. 2016. Manual Básico de Derecho Administrativo. 13a ed. Madrid: Tecnos.

García de Enterría, Eduardo y Fernández, Tomás-Ramón. 2002. Curso de Derecho Administrativo. Tomos I. 11a ed. Madrid: Civitas.
García de Enterría, Eduardo y Fernández, Tomás-Ramón. 2002. Curso de Derecho Administrativo. Tomos II. 8a ed. Madrid: Civitas.

Gonzáles Navarro, Francisco. 1965. La presentación indirecta de ofertas públicas en los procedimientos de selección de contratistas. Revista de Administración Pública No 46.

Gonzáles Navarro, Francisco. 1981. Procedimiento administrativo común, procedimientos triangulares y procedimientos complejos. Revista de Estudios de la Vida Local No 211.

Gordillo, Agustín. 1992. El informalismo y la concurrencia en la licitación pública. Revista do Tribunal Regional do Trabalho, Vol. 17.

Guastini, Riccardo. 2016. La Sintaxis del Derecho. Traducción de Álvaro Núñez. Madrid: Marcial Pons.

López Menudo, Francisco. 1992. Los principios generales del procedimiento administrativo". Revista de Administración Pública, No 129.

Marienhoff, Miguel. 1966. Tratado de Derecho Administrativo. Contratos Administrativos. Tomo III-A. Buenos Aires: AbeledoPerrot.

Morón Urbina, Juan Carlos. 2011. "Los procedimientos administrativos: Contribución para su útil clasificación", en La Ley de Procedimiento Administrativo General. Diez Años Después. Libro de ponencias de las Jornadas por los 10 años de la Ley de Procedimiento Administrativo General. Lima: Palestra.

Morón Urbina, Juan Carlos. 2016. La Contratación Estatal. Lima: Gaceta Jurídica.

Tawil, Guido Santiago. 2010. "El procedimiento administrativo como instrumento de control de la Administración y garantía de los administrados". En: Tawil, G. (Director) Procedimiento Administrativo. Buenos Aires: Abeledo Perrot. 


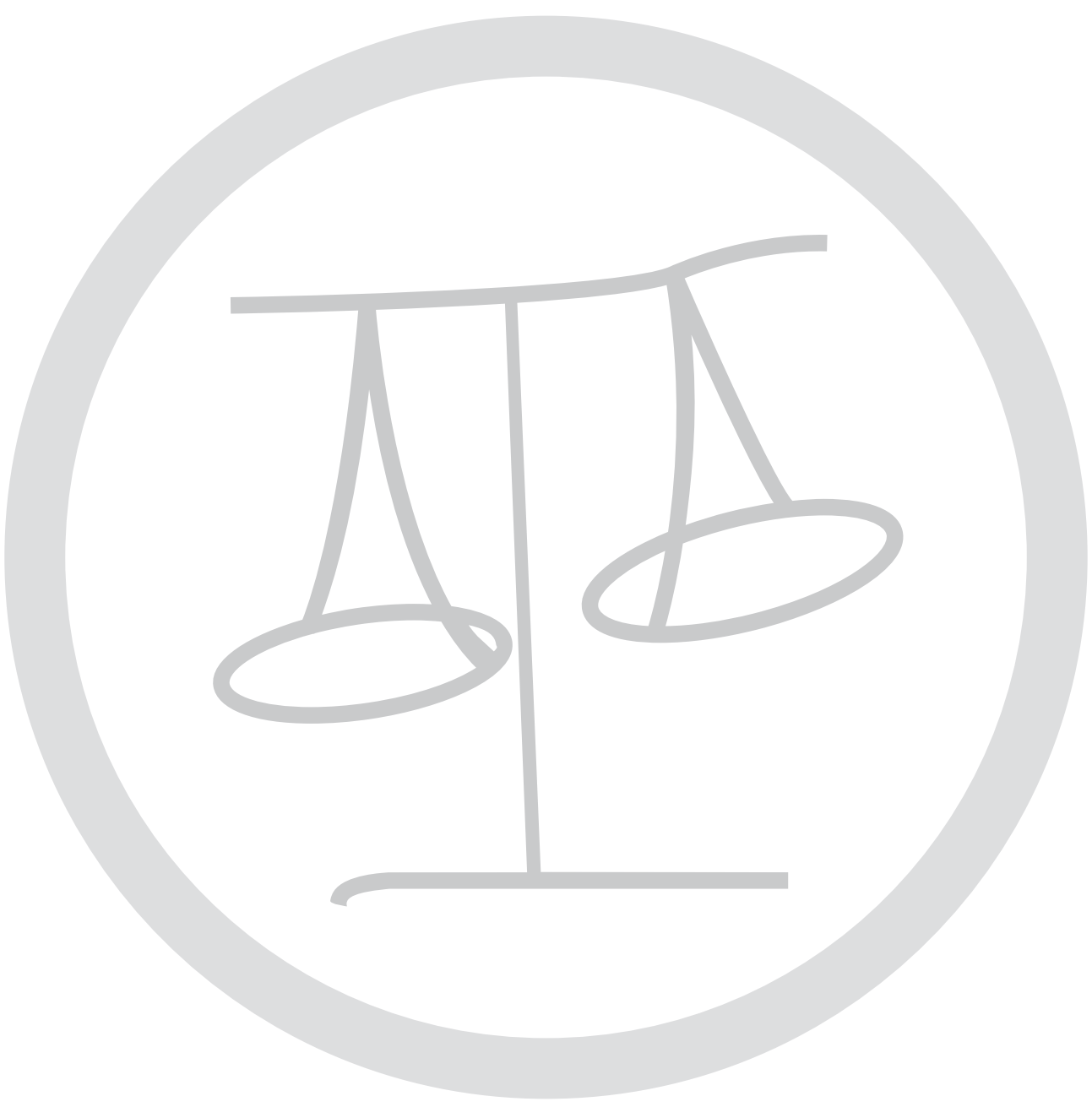

